\title{
Relationship between Hemolysis and Resistance to Antibiotics among Clinical Isolates of Escherichia Coli from Urine
}

\author{
Moamen Al Zoubi ${ }^{1 *}$, Megan Farrington ${ }^{2}$, and Steven Hatch ${ }^{1}$ \\ ${ }^{1}$ University of Massachusetts Memorial Medical Center, Worcester, MA, USA \\ ${ }^{2}$ Quest Diagnostics, Microbiology Supervisor, USA
}

*Corresponding author: Al Zoubi M, University of Massachusetts Memorial Medical Center, Worcester, MA, USA, E-mail: moamen.alzoubi@ gmail.com

Received: 01 Jun, 2020 | Accepted: 28 Aug, 2020 | Published: 08 Sep, 2020

Citation: Al Zoubi M, Farrington M, Hatch S (2020) Relationship between Hemolysis and Resistance to Antibiotics among Clinical Isolates of Escherichia Coli from Urine. Clin Res Open Access 6(2): dx.doi.org/10.16966/2469-6714.159

Copyright: (C) 2020 Al Zoubi M, et al. This is an open-access article distributed under the terms of the Creative Commons Attribution License, which permits unrestricted use, distribution, and reproduction in any medium, provided the original author and source are credited.

\section{Abstract}

E.coli is responsible for many community-onset and nosocomial infections. The increasingly high level of antimicrobial drug resistance prevalence is a worsening problem. $E$. coli has many resistance mechanisms. In some cases, these mechanisms confer additional virulence of the pathogen. $E$. coli can produce several types of hemolysin, including an extracellular protein ( $\alpha$-hemolysin), a cell-bound protein ( $\beta$-haemolysin) and a hemolysin expressed by nalidixic acid-resistant mutants ( $\gamma$-hemolysin). A-Hemolysin is a virulence factor in strains causing different extra-intestinal infections [1]. It can induce osmotic lysis of erythrocytes due to its pore-forming activity, and is cytotoxic to several types of human cell [2]. This study was undertaken to evaluate the relationship between hemolysin production and resistance to antibiotics among clinical isolates of $E$. coli from urine.

Keywords: Antimicrobial stewardship

\section{Methods}

We reviewed $1792 \mathrm{E}$ coli isolates in urine cultures from UMASS Memorial Medical Center between November 2017 to April 2018. These isolates were either hemolytic strain (HEC) or non-hemolytic strain (NHEC). Hemolysis was identified by comparing the growth characteristics and colony morphology seen on TSA II with 5\% sheep blood/MacConkey agar of lactose-fermenting, non-mucoid, gram negative colonies. HEC produce a zone of beta-hemolysis that is visible on TSA II agar. Further biochemical testing was performed to confirm the identification of $E$. coli. The percentage of antibiotics resistance was compared between two groups. The Vitek system uses anextended-spectrum $\beta$-lactamase (ESBL) screening well and compares the resistance pattern using phenotypic software to determine if the isolate is ESBL. The screening well contains cefepime, ceftazidime, and cefotaxime, with and without clavulanic acid, to determine positive and negative. The results were logged as ESBL-positive or ESBL-negative. We matched 110 ESBL E. coli isolates to 110 non-ESBL $E$. coli isolates, and antibiotic susceptibility was compared. The statistical significance of differences in resistance to antimicrobial agents between hemolytic and non-hemolytic isolates was tested using the chi-square test or Fisher's exact test, when expected cell sizes were less than 5 . Differences were considered significant when $\mathrm{P}$ was $<0.05$.

Results

Among all E. coli isolates, 479(26.7\%) were HEC while 1313(73.2\%) isolate were NHEC. The percentage of ESBL isolates among both groups was the same (6\%). NHEC isolates were more likely to be resistant to fluoroquinolones when compared to HEC (10\% vs $4 \% \mathrm{P}=0.0004$ for ciprofloxacin: $5.8 \%$ vs $0.8 \% \mathrm{P}=0.0001$ for levofloxacin). NHEC isolates were also more likely to be resistant to cefepime when compared to HEC ( $2.7 \%$ vs. $0.9 \% \mathrm{P}=0.02)$ (Table 1). There was no significant difference among other antibiotics between two groups. Among the ESBL group, 83 isolates (75.5\%) were NHEC while 27 (24.5\%) were HEC. The percentage of resistance to antibiotics was not statistically significant between the two groups (Table 2). Among the non-ESBL E. coli isolates, $73(66.4 \%)$ were NHEC while 37 (33.6\%) were HEC. Similarly, the percentage of resistance to antibiotics was not significantly different between the two groups (Table 3).

\section{Conclusion}

The percentages of isolates with resistance to both levofloxacin ciprofloxacin, cefepime but not to other agents, were significantly higher $(\mathrm{P}<0.05)$ among NHEC isolates than among HEC isolates. Although fluoroquinolone use is now discouraged, this finding may represent a narrow indication for its use in certain clinical scenarios [3-6].

\section{Disclosures}

All authors: No reported disclosures. 
Table 1: Antibiotics Resistance (\% Resistance).

\begin{tabular}{|l|c|c|c|}
\hline \multicolumn{1}{|c|}{ Antibiotics } & $\begin{array}{c}\text { Hemolytic E.Coli } \\
\text { (N:479) }\end{array}$ & $\begin{array}{c}\text { Non-Hemolytic } \\
\text { E.Coli (N:1313) }\end{array}$ & p Value \\
\hline Ciprofloxacin & $4 \%$ & $10 \%$ & 0.0004 \\
\hline Levofloxacin & $0.8 \%$ & $5.8 \%$ & 0.0001 \\
\hline Cefepime & $2.7 \%$ & $0.9 \%$ & 0.02 \\
\hline Piperacillin/ tazobactam & $1 \%$ & $0.1 \%$ & 0.93 \\
\hline Amikacin & $0.2 \%$ & $0.00 \%$ & 0.16 \\
\hline Ceftazidime & $2 \%$ & $1.5 \%$ & 0.48 \\
\hline Positive ESBL & $6 \%$ & $6 \%$ & 0.65 \\
\hline
\end{tabular}

Table 2: Antibiotics Resistance among ESBL isolates (\% Resistance).

\begin{tabular}{|l|c|c|c|}
\hline \multicolumn{1}{|c|}{ Antibiotics } & $\begin{array}{c}\text { ESBL Hemolytic } \\
\text { E.Coli (N:27) }\end{array}$ & $\begin{array}{c}\text { ESBL Non-Hemolytic } \\
\text { E.Coli (N:83) }\end{array}$ & p Value \\
\hline Ciprofloxacin & $59.20 \%$ & $66.20 \%$ & 0.57 \\
\hline Levofloxacin & $55.4 \%$ & $51.80 \%$ & 0.36 \\
\hline Cefepime & $48.10 \%$ & $32.50 \%$ & 0.2 \\
\hline $\begin{array}{l}\text { Piperacillin/ } \\
\text { tazobactam }\end{array}$ & $25.9 \%$ & $16.80 \%$ & 0.37 \\
\hline Ceftazidime & $37.00 \%$ & $26.50 \%$ & 0.36 \\
\hline Amikacin & $0.0 \%$ & $0.00 \%$ & 0.99 \\
\hline Positive blood culture & $3.7 \%$ & $7.20 \%$ & 0.99 \\
\hline
\end{tabular}

Table 3: Antibiotics Resistance among non ESBL isolates (\% Resistance).

\begin{tabular}{|l|c|c|c|}
\hline \multicolumn{1}{|c|}{ Antibiotics } & $\begin{array}{c}\text { Hemolytic E.Coli } \\
\text { (N:37) }\end{array}$ & $\begin{array}{c}\text { Non-Hemolytic } \\
\text { E.Coli (N:73) }\end{array}$ & p Value \\
\hline Ciprofloxacin & $5.40 \%$ & $11 \%$ & 0.35 \\
\hline Levofloxacin & $2.70 \%$ & $8.30 \%$ & 0.42 \\
\hline Cefepime & $0.00 \%$ & $0.00 \%$ & 0.99 \\
\hline $\begin{array}{l}\text { Piperacillin/ } \\
\text { tazobactam }\end{array}$ & $2.70 \%$ & $2.70 \%$ & 0.99 \\
\hline Ceftazidime & $0.00 \%$ & $2.70 \%$ & 0.55 \\
\hline Amikacin & $0.00 \%$ & $1.30 \%$ & 0.99 \\
\hline
\end{tabular}

Citation: Al Zoubi M, Farrington M, Hatch S (2020) Relationship between Hemolysis and Resistance to Antibiotics among Clinical Isolates of 